\title{
Surface Expression of the Netrin Receptor UNC5H1 Is Regulated through a Protein Kinase C-Interacting Protein/Protein Kinase-Dependent Mechanism
}

\author{
Megan E. Williams, ${ }^{\star}$ Sareina C.-Y. Wu, ${ }^{\star}$ William L. McKenna, ${ }^{\star}$ and Lindsay Hinck \\ Department of Molecular, Cell, and Developmental Biology, University of California, Santa Cruz, California 95064
}

\begin{abstract}
Netrin-1 is a bifunctional guidance cue that directs migrating neurons and axons based on specific receptors expressed on the cell surface. Attraction occurs through the receptor Deleted in Colorectal Cancer (DCC) and repulsion occurs through a receptor complex of DCC and $\mathrm{UNC} 5 \mathrm{H}$, the vertebrate homolog to Caenorhabditis elegans UNC-5, but how the specific surface expression of these receptors is achieved remains unknown. Here, we demonstrate that surface expression of UNC5H1 is regulated in neurons by protein interacting with $\mathrm{C}$ kinase-1 (PICK1) and protein kinase C (PKC), and show that one mechanism by which cells control their response to netrin-1 is by changing the surface availability of receptors. We identified PICK1 as a binding partner for UNC5H1 using the yeast two-hybrid system and found that the extreme three C-terminal amino acids of UNC5H1 interact with the PSD-95/Dlg/ZO-1 (PDZ) domain of PICK1. Coexpression of UNC5H1 and PICK1 in heterologous cells results in the recruitment of PICK1 to UNC5H1 clusters. Endogenous UNC5H1 and PICK1 coimmunoprecipitate from extracts of cultured hippocampal neurons and P4 cortices, and immunohistochemistry shows that UNC5H1, PICK1, and PKC are all present in growth cones. PKC activation induces the formation of UNC5H1/PICK1/PKC complexes and leads to the specific removal of UNC5H1, but not DCC, from the surface of neurons and growth cones via a PICK1/PKC-dependent mechanism. Lastly, we demonstrate that activating PKC, which decreases surface expression of UNC5H1, inhibits netrin-1-dependent collapse of hippocampal growth cones. Together, our results suggest that by regulating the surface expression of UNC5Hs, an axon can modulate its repellent response to netrin-1.
\end{abstract}

Key words: UNC5H; netrin; PICK1; PKC; axon guidance; receptor trafficking

\section{Introduction}

In the developing nervous system, cells and axons respond to a variety of attractive and repellent guidance cues en route to their final destination. Often, they follow a complicated trajectory using multiple cues. As a result, some cells switch responsiveness to a particular cue or respond to new cues in the environment (Bloch-Gallego et al., 1999; Alcantara et al., 2000; Finger et al., 2002; Shewan et al., 2002). Studies show that concentration changes in global signaling molecules, like cAMP and calcium, affect the response of a cell to guidance molecules (for review, see Song and Poo, 1999; Petersen and Cancela, 2000). However, little is known about receptor-mediated mechanisms controlling this process at the cell surface.

The secreted molecule netrin-1 is a guidance cue capable of bidirectional signaling. Netrin-1 promotes attraction of neurons and axons through the receptor Deleted in Colorectal Cancer (DCC) (Keino-Masu et al., 1996) and repulsion through a receptor complex of DCC and UNC5Hs, the vertebrate homolog to

\footnotetext{
Received June 11, 2003; revised Aug. 26, 2003; accepted 0ct. 9, 2003.

This work was supported by National Institutes of Health Grants NS39572-01 (L.H.) and MH12813-02 (M.E.W.) and March of Dimes Birth Defects Foundation Grant 5-FY99-765. We thank David Feldheim for donating Sindbis virus reagents, Alex Toker for providing the $P K C \alpha$-Flag pCMV5 construct, and Yishi Jin for use of her confocal microscope. *M.E.W., S.C.-Y.W., and W.L.M. contributed equally to this work.

Correspondence should be addressed to Dr. Lindsay Hinck, Sinsheimer Laboratories, University of California, Santa Cruz, CA 95064. E-mail: hinck@biology.ucsc.edu.

Copyright $\odot 2003$ Society for Neuroscience $\quad 0270-6474 / 03 / 2311279-10 \$ 15.00 / 0$
}

Caenorhabditis elegans UNC-5 (Hong et al., 1999). The vertebrate UNC5Hs (UNC5H1, 2, 3, and 4) (Ackerman et al., 1997; Leonardo et al., 1997; Engelkamp, 2002), the C. elegans UNC-5 (Hedgecock et al., 1990; Leung-Hagesteijn et al., 1992), and Drosophila UNC5 (Keleman and Dickson, 2001) are members of the Ig superfamily of transmembrane receptors that directly bind netrin-1. In addition to their role in netrin-1-dependent axon guidance, the UNC5Hs also mediate netrin-1-independent apoptosis (Llambi et al., 2001; Tanikawa et al., 2003; Williams et al., 2003). Currently, little is known about the downstream molecules that bind UNC5Hs and affect their signal transduction (Tong et al., 2001; Williams et al., 2003).

Protein interacting with C kinase-1 (PICK1) was initially identified by its interaction with the catalytic subunit of protein kinase $\mathrm{C} \alpha$ (PKC $\alpha$ ) (Staudinger et al., 1995). It contains a coiledcoil domain that mediates homotypic dimerization and a PDZ domain that mediates its interaction with the $\mathrm{C}$ termini of proteins (Staudinger et al., 1995, 1997). PICK1 is best characterized for its role in clustering and trafficking the AMPA receptor during synaptic plasticity (Xia et al., 1999; Chung et al., 2000; Daw et al., 2000; Perez et al., 2001; Hirbec et al., 2003). It is thought that PICK1 facilitates AMPA-receptor phosphorylation by bringing it in close proximity to PKC (Xia et al., 1999; Chung et al., 2000). Phosphorylation of the AMPA receptor by PKC rapidly changes its subcellular localization, which affects its ability to function at synapses (Chung et al., 2000; Daw et al., 2000). These and other 
studies on PICK1 suggest that it functions as a targeting and transport protein, directing the activated form of $\mathrm{PKC}$ to receptors.

Here, we show that the netrin-1 receptor UNC5H1 associates with PICK1 and PKC. Furthermore, PKC stimulation promotes the removal of UNC5H1 from the cell surface of hippocampal neurons and growth cones, and decreases the ability of netrin-1 to induce the collapse of growth cones. The discovery that surface levels of $\mathrm{UNC} 5 \mathrm{H} 1$ are regulated via PICK1 and PKC suggests that one mechanism by which cells and axons alter their response to guidance cues is by modulating receptor availability at the cell surface.

\section{Materials and Methods}

Constructs and reagents. The original full-length, rat Unc5h1, Unc5h2, and Unc5h 3 constructs in pSecTagB (Invitrogen, San Diego, CA) (Leonardo et al., 1997; Hong et al., 1999; Williams et al., 2003) were modified by PCR cloning to move the Myc tag from the $\mathrm{C}$ terminus to the $\mathrm{N}$ terminus of the UNC5Hs. Full-length PICK1 was isolated in the yeast two-hybrid screen and cloned into pcDNA3.1 with a C-terminal Flag tag. MycUnc5h1 3 C and Pick1-FlK27A,D28A mutants were generated using Stratagene (La Jolla, CA) QuikChange Site Directed Mutagenesis kit according to the manufacturer's protocol. MycUnc5h1 and Pick1-Fl DNA, including a consensus Kozak and start site, were cloned into the viral vector pSinRep5 (Invitrogen) using the XbaI site. All PCR products and mutations were verified by sequencing.

Yeast two-hybrid analysis and glutathione S-transferase pull-down assay. The E15.5 mouse brain library was made according to manufacturer's instructions using a Stratagene cDNA synthesis kit and ligated into the EcoRI/XhoI sites in pACT2 (Clontech, Cambridge, UK) that contains a Gal4-activating domain. The UNC5H1 intracellular bait (H1ICD) in pBTM116 was fused in-frame with a LexA DNA-binding domain (Hong et al., 1999). DNA was transformed into the L40 yeast strain stably transfected with a LexA-driven HIS3 gene and LexA-driven LacZ gene (Vojtek et al., 1993). Transformants were selected for the ability to grow on minus histadine plates supplemented with $30 \mathrm{~mm} 3$-amino1,2,4-triazole and subsequently screened for the ability to produce LacZ. Glutathione $S$-transferase (GST) pull-down assays were performed as described previously (Williams et al., 2003).

Cell culture and transfections. COS cells were maintained in DMEM supplemented with 10\% FBS and transfected using FuGENE (Roche, Hertfordshire, UK). Sindbis virus expressing MycUnc5h1 or Pick1-Fl was packaged in baby hamster kidney (BHK) cells grown in MEM as described by the manufacturer's protocol (Invitrogen) and virus was diluted 1:40 to infect hippocampal neurons.

Hippocampal cultures and infection. Hippocampal neurons were harvested from embryonic day 18 rat tissue as described previously (Osten et al., 1998), plated on coverslips at $9.5 \times 10^{3} \mathrm{cells} / \mathrm{cm}^{2}$ for immunohistochemistry or $2.5 \times 10^{5}$ cells $/ \mathrm{cm}^{2}$ for immunoprecipitation and biotinylation experiments, and maintained in Neurobasal A medium with B27 supplement (Invitrogen, Gaithersburg, MD). Pseudovirion-containing medium was prepared from electroporated BHK cells as directed by the Sindbis Expression System (Invitrogen). Cells were incubated with infectious medium for $1 \mathrm{hr}$, returned to Neurobasal medium without virus, and immunostained $30 \mathrm{hr}$ later.

Immunoprecipitation and Western blotting. COS cells or hippocampal neurons were immunoprecipitated as described previously (Hong et al., 1999). Briefly, cells were incubated in lysis buffer (50 mM Tris, $150 \mathrm{~mm}$ $\mathrm{NaCl}, 5 \mathrm{~mm}$ EDTA, 1\% Triton X-100, and 10\% glycerol, $\mathrm{pH} 7.5$ ) containing aprotinin, leupeptin, and PMSF at $1 \mu \mathrm{g} / \mathrm{ml}$ each. The samples were rocked at $4^{\circ} \mathrm{C}$ for $40 \mathrm{~min}$ and then pelleted in a microfuge at $14,000 \times g$ (full speed) for $20 \mathrm{~min}$. The supernatant was then incubated with antibody prebound to protein A/G (Santa Cruz Biotechnology, Santa Cruz, CA) for $3 \mathrm{hr}$ at $4^{\circ} \mathrm{C}$. Western blots were visualized using ECL detection (Amersham Biosciences, Arlington Heights, IL). For the endogenous coimmunoprecipitations, $\sim 1.5 \times 10^{7}$ hippocampal neurons grown $7 \mathrm{~d}$ in vitro (DIV) or two postnatal day 4 (P4) mouse cortices were used per immunoprecipitation. Cortices were homogenized in lysis buffer using progressively smaller-bore Pasteur pipettes; then immunoprecipitations were performed as for cultured cells. The following antibodies were diluted to $1 \mu \mathrm{g} / \mathrm{ml}$ and used for Western blots: anti-Myc 9E10, anti-PICK1 N18 (Santa Cruz Biotechnology), anti-UNC5H1 3E5, anti-Flag M2 (Sigma, St. Louis, MO), and anti-DCC Ab-1 (Oncogene Sciences, Uniondale, NY).

Immunostaining and antibodies. Hippocampal neurons were treated with $100 \mathrm{ng} / \mathrm{ml}$ TPA (phorbol 12-myristate 13-acetate; Sigma) for $1 \mathrm{hr}$. For live labeling of surface proteins, cells were incubated at $37^{\circ} \mathrm{C}$ with primary antibody plus $0.1 \%$ sodium azide to prevent internalization for $30 \mathrm{~min}$. Cells were washed with PBS, fixed, and permeabilized with methanol at $-20^{\circ} \mathrm{C}$ for $15 \mathrm{~min}$. Background staining was prevented by blocking in PBS $+3 \%$ heat-inactivated goat serum (Invitrogen) for $30 \mathrm{~min}$. To label intracellular proteins, cells were next incubated with the appropriate primary antibody for $1 \mathrm{hr}$ at room temperature or overnight at $4^{\circ} \mathrm{C}$. Cells were incubated with secondary antibody at room temperature for 45 min, washed thoroughly with PBS, and coverslipped using Fluoromount G (Southern Biotechnology, Alabaster, AL). Antibodies for immunostaining were used as follows: MycH1 live label; chicken anti-Myc 1 $\mu \mathrm{g} / \mathrm{ml}$ (Aves Labs, Tigard, OR), MycH1 fixed label; rabbit anti-Myc (A14) $1 \mu \mathrm{g} / \mathrm{ml}$ (Santa Cruz Biotechnology), $0.4 \mu \mathrm{g} / \mathrm{ml}$ anti-Flag $\mathrm{M} 2$ (Sigma), $1.7 \mu \mathrm{g} / \mathrm{ml}$ anti-PICK1 (Affinity BioReagents, Golden, CO), 0.6 $\mu \mathrm{g} / \mathrm{ml}$ anti-PKC $\alpha$ (BD Biosciences, San Jose, CA), and $5 \mu \mathrm{g} / \mathrm{ml} 2026$ anti-UNC5H1.

Biotinylation. Twenty-four hours after infection, hippocampal cells were treated with $100 \mathrm{ng} / \mathrm{ml} \mathrm{TPA}$ and incubated at $37^{\circ} \mathrm{C}$ for $60 \mathrm{~min}$. Cells were washed twice with ice-cold HEPES-buffered Ringers solution (HBR: $10 \mathrm{~mm}$ HEPES, $150 \mathrm{~mm} \mathrm{NaCl}, 7.2 \mathrm{~mm} \mathrm{KCl}$, and $2.25 \mathrm{~mm} \mathrm{CaCl}_{2}$, $\mathrm{pH}$ 7.5). The cells were then incubated in $1 \mathrm{mg} / \mathrm{ml}$ Sulfo-biotin (Pierce, Rockford, IL) in $\mathrm{HBR}$ at $4^{\circ} \mathrm{C}$ for $20 \mathrm{~min}$. To quench the excess biotin, cells were washed twice for $20 \mathrm{~min}$ each in HBR $+100 \mathrm{~mm}$ glycine. Finally, cells were washed with cold Tris-buffered saline, lysed with immunoprecipitation buffer, and immunoprecipitated using Immobilized NeutrAvidin agarose beads (Pierce). Controls were performed to confirm that intracellular proteins were not biotin-labeled.

Collapse assay. Two hours after plating, hippocampal neurons were infected with a Sindbis virus containing both Unc5h1 and green fluorescent protein (GFP) on a single plasmid (Invitrogen). Twenty-four hours later, the cells were treated with TPA $(100 \mathrm{ng} / \mathrm{ml})$ or a control and incubated at $37^{\circ} \mathrm{C}$ for $1 \mathrm{hr}$. Next, purified netrin- 1 (300 ng/ml) was added to some cultures for $45 \mathrm{~min}$. Cells were then fixed in PBS containing $4 \%$ PFA and $4 \%$ sucrose for 15 min. Single cells with clearly defined axons expressing GFP were examined for growth cone collapse using $63 \times$ phase-contrast microscopy on a Zeiss (Oberkochen, Germany) Axiovert 200. For quantitation, a growth cone was considered collapsed if it had no lamellipodia and two or fewer filopodia. Each experimental condition was repeated three or more times and 50 random growth cones were examined per experiment.

Statistics and image analysis. For the quantitative immunofluorescence assay, all images were acquired with a Zeiss LSM 5 Pascal confocal microscope at $63 \times$ magnification. The laser intensity, exposure, and gain settings were the same for each image. Segments of individual axons and dendrites were excised from the images, and color channels were split and converted to grayscale using Adobe Photoshop (San Jose, CA). Images were thresholded (150 on a scale from 0 to 255 ) to exclude background staining and then analyzed with Scion (Frederick, MD) Image 1.63. Fluorescent surface area from each antibody (intracellular or extracellular) was calculated from a constant total cell area. Mean cell segment values ( $n \geq 2$ per cell) were calculated. This was repeated on multiple cells from independent rat hippocampal preparations ( $n \geq 15$ cell;, $n \geq 3$ rats). Biotinylation experiments were quantified using NIH Image software(NIH, Bethesda, MD. Multiple Western blot exposures from several experiments $(n=5)$ were scanned, and band intensities were analyzed. Statistics were performed using Excel (Microsoft, Seattle, WA) software.

\section{Results}

UNC5H1 binds PICK1 through a PDZ interaction

To identify molecules involved in UNC5H1 signal transduction, we performed a yeast two-hybrid screen on an E15.5 murine 
brain library using the intracellular domain of UNC5H1 (H1ICD) as bait. One molecule identified was PICK1, a PDZ protein known to regulate AMPA-receptor trafficking (Xia et al., 1999; Boudin et al., 2000; Chung et al., 2000; Daw et al., 2000; Perez et al., 2001; Hanley et al., 2002; Hirbec et al., 2003). We initially mapped the interaction between UNC5H1 and PICK1 using the yeast two-hybrid system. Deleting the C-terminal death domain of UNC5H1 (H1 $1 \mathrm{DD})$ abolished the interaction with PICK1 (Fig. 1A). Previous studies demonstrated that PICK1 typically interacts with receptors through PDZ-binding domains at their extreme C terminals (Torres et al., 1998, 2001; Xia et al., 1999; Boudin et al., 2000; Dev et al., 2000; Lin et al., 2001; Duggan et al., 2002; Hirbec et al., 2003). To test whether this is true for $\mathrm{UNC} 5 \mathrm{H} 1$, we truncated the last three amino acids $(\mathrm{H} 1 \Delta 3 \mathrm{C})$ and found that this was sufficient to prevent the interaction with PICK1 (Fig. 1A). A construct expressing only the death domain, including the last three amino acids, still interacts, although more weakly, with PICK1 (Fig. 1A). These results indicate that the UNC5H1-PICK1 interaction requires the last three amino acids of the UNC5H1 cytoplasmic tail.

The failure of $\mathrm{H} 1 \Delta 3 \mathrm{C}$ to interact with PICK1 suggested that the interaction is mediated through the PDZ domain of PICK1. To test this, we deleted the PDZ domain of PICK1 (PICK1 $\Delta 110$ ) and observed no interaction with H1ICD (Fig. 1A). Although, the C-terminal amino acids of UNC5H1, alanine, glutamic acid, and cysteine (AEC), are not a typical consensus PDZ-binding domain, several studies show that PICK1 interacts with multiple PDZ-binding sequences, including atypical motifs (Lin et al., 2001; Hirbec et al., 2002).

To determine whether the interaction between UNC5H1 and PICK1 results from direct protein binding, we performed a GST pull-down assay. Purified GST-H1ICD strongly interacted with in vitro-translated, ${ }^{35}$ S-labeled PICK1, whereas GST alone showed little nonspecific binding (Fig. $1 B$ ). This result demonstrates that a direct interaction occurs between UNC5H1 and PICK1. We then tested the interaction between UNC5H1 and PICK1 by precipitating Pick1-transfected COS cells with GSTH1ICD or GST alone and Western blotting with an anti-PICK1 antibody. Again, PICK1 was precipitated by GST-H1ICD and not by GST alone (Fig. $1 B$ ).

Next, we tested whether other members of the UNC5H family interact with PICK1 by coimmunoprecipitation. COS cells were transiently transfected with full-length Myc-tagged Unc5h1, Unc5h2, or Unc5h3 and full-length Pick1. PICK1 was immunoprecipitated with anti-Myc antibodies when MycUNC5H1 (MycH1), but not empty vector, was cotransfected (Fig. 1C). In addition, we found that $\mathrm{MycH} 2$ interacted with PICK1, although slightly less well than $\mathrm{MycH} 1$, and that $\mathrm{MycH} 3$ showed very little interaction with PICK1 (Fig. 1C). These results were not surprising, based on sequence comparisons of the last three amino acids of the UNC5Hs. The C terminus of UNC5H2, GDC, is similar to the AEC of UNC5H1 in that they both contain an acidic residue followed by a cysteine residue, whereas the amino acids at the $\mathrm{C}$ terminus of UNC5H3, GQY, do not share these characteristics.

We then tested whether truncating the last three amino acids of UNC5H1 would prevent the interaction with PICK1 in cells by coimmunoprecipitation. Very little PICK1 coimmunoprecipitated with $\mathrm{MycH} 1 \Delta 3 \mathrm{C}$ compared with the amount coprecipitated by full-length $\mathrm{MycH} 1$ (Fig. 1D). A PICK1 double point mutant K27A,D28A (PICK1KD/AA) was also tested for its ability to interact with $\mathrm{MycH} 1$ in cells. These mutations in PICK1KD/AA reside in the carboxylate-binding loop of the PDZ domain and interfere with PDZ interactions, including the interaction be- tween PICK1 and PKC $\alpha$ (Staudinger et al., 1997; Xia et al., 1999). Accordingly, we found that PICK1KD/AA did not coimmunoprecipitate with $\mathrm{MycH1}$ (Fig. 1D). These observations indicate that the interaction between UNC5H1 and PICK1 is likely to occur between a PDZ-binding domain at the $\mathrm{C}$ terminus of UNC5H1 and the PDZ domain of PICK1.

Lastly, we examined whether UNC5H1 binds to PICK1 in vivo. Endogenous UNC5H1 from both rat hippocampal neurons and murine P4 cortices was immunoprecipitated with 6E9, an antibody specific to UNC5H1 (Williams et al., 2003). In both cases, PICK1 coimmunoprecipitated with anti-UNC5H1 but not with a control antibody (Fig. $1 E$ ), indicating that UNC5H1 and PICK1 associate in vivo.

\section{UNC5H1 and PICK1 colocalize in heterologous cells}

Expression of UNC5H1 in heterologous cells resulted in a punctate pattern of UNC5H1 localization (Fig. 2A) (Huang et al., 2002). In contrast, PICK1 expression was normally diffuse throughout the cytoplasm (Fig. $2 B$ ) but became punctate when coexpressed with cognate receptors (Torres et al., 1998; Xia et al., 1999; Boudin et al., 2000). Therefore, we asked whether coexpression of UNC5H1 and PICK1 affects the localization of either protein. Cotransfection and immunostaining of $\mathrm{MycH} 1$, together with Flag-tagged PICK1 (PICK1-Fl), showed PICK1-Fl in a punctate pattern overlapping with UNC5H1 expression (Fig. $2 C-E)$. Coexpressing either the $\mathrm{MycH} 1 \Delta 3 \mathrm{C}$ mutant with wildtype PICK1-Fl (Fig. $2 \mathrm{~F}-\mathrm{H}$ ) or wild-type MycH1 with PICK1FlKD/AA (Fig. $2 I-K$ ) did not result in a similar recruitment of PICK1 to clusters, but instead PICK1 remained diffuse in the cytoplasm. These data, demonstrating colocalization of UNC5H1 and PICK1, further support our finding that UNC5H1 and PICK1 interact when expressed together in cells.

\section{UNC5H1, PICK1, and PKC colocalize in the growth cone}

Next, we determined whether endogenous levels of UNC5H1 and PICK1 are present together in the growth cone. After 2 DIV, rat hippocampal neurons plated at low density begin to send out axonal projections that have, at their tip, a leading growth cone (Fig. 3A,E). To examine endogenous UNC5H1 expression, we generated a rabbit polyclonal antibody against the intracellular domain of UNC5H1 (2026); 2026 specifically recognized UNC5H1, but not UNC5H2 or UNC5H3, by immunohistochemistry in transfected COS cells (data not shown).

We used 2026 to immunostain 2 DIV hippocampal neurons and observed UNC5H1 expression in growth cones (Fig. 3A,B). We also coimmunostained the neurons for PKC $\alpha$ because PICK1 functions as an adaptor molecule for $\mathrm{PKC} \alpha$, bringing it in close proximity with transmembrane receptors (Staudinger et al., $1995,1997)$. Our results showed that PKC $\alpha$ was present at sites of UNC5H1 expression in the growth cone (Fig. $3 A-D$ ). Next, we immunostained 2 DIV hippocampal neurons using antibodies to PICK1 and PKC $\alpha$ and found that PICK1 also colocalized with PKC $\alpha$ (Fig. 3E-H). Thus, UNC5H1, PICK1, and PKC $\alpha$ are expressed endogenously in growth cones.

\section{UNC5H1, PICK1, and PKC $\alpha$ form a complex after PKC activation}

Previous work suggests that PICK1 dimers function as a scaffolding molecule, bringing $\mathrm{PKC} \alpha$ in close proximity to receptors (Staudinger et al., 1997; Xia et al., 1999; Chung et al., 2000). Given that UNC5H1, PICK1, and PKC $\alpha$ were simultaneously expressed in the growth cone (Fig. $3 A-H$ ), we used coimmunoprecipitation to test whether these molecules associate with each other to form 
A.
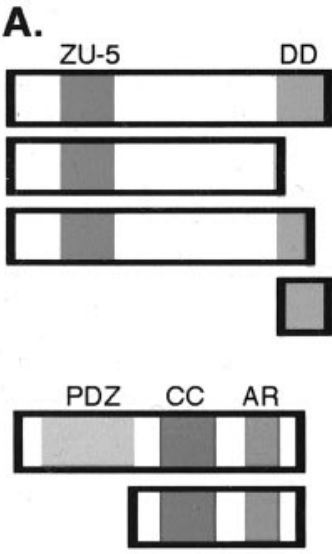

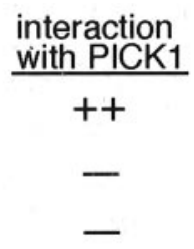

$+$

PICK1 1110

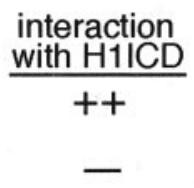

\section{PICK1 bait \\ PICK1}

B.
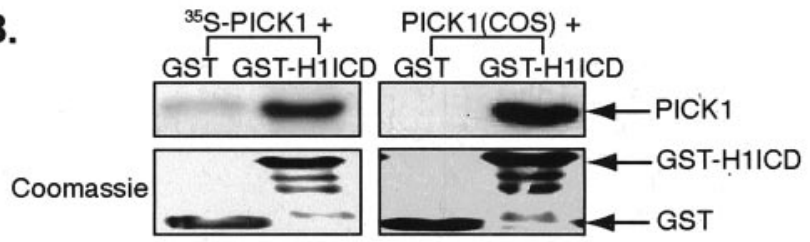

C.
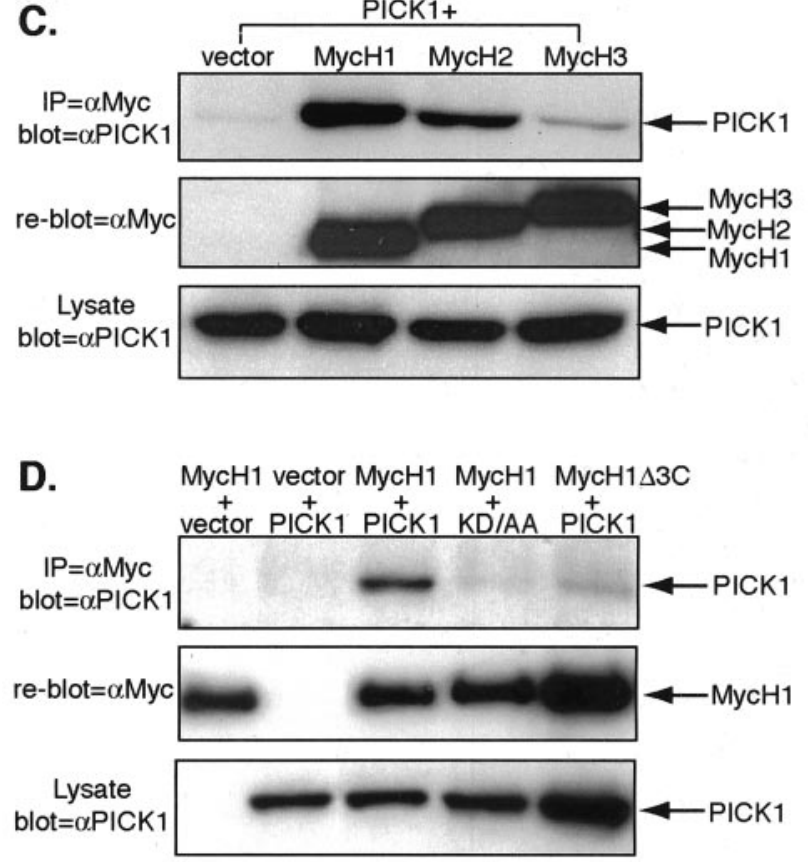

E.

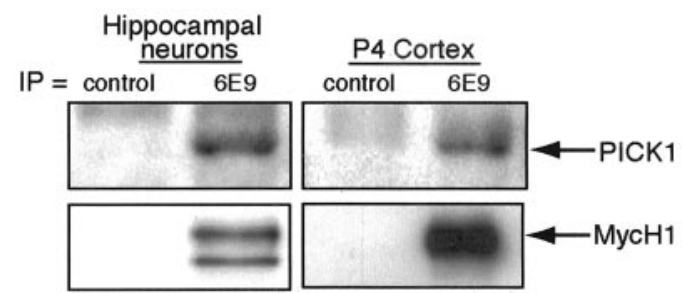

Figure 1. UNC5H1 directly interacts with PICK1 in vitro and in vivo. $A$, The schematic diagram shows UNC5H1 intracellular domain (H1ICD) and PICK1 deletion constructs. ++, Excellent ability to grow on histidine selection; + , some growth; - , no growth. B, GST or GST-H1ICD were incubated with in vitro-translated ${ }^{35} \mathrm{~S}$-PICK1 or lysate from COS cells transiently transfected with Pick1. Glutathione agarose beads were used to pull down the GST molecules, and the samples were separated by SDS-PAGE. Autoradiography was used to detect coprecipitating ${ }^{35}$ S-PICK1 (left top) and a Western blot using anti-PICK1 antibodies was used to detect PICK1 from COS lysates (right top). The Coomassie-stained gels show that equivalent amounts of GST
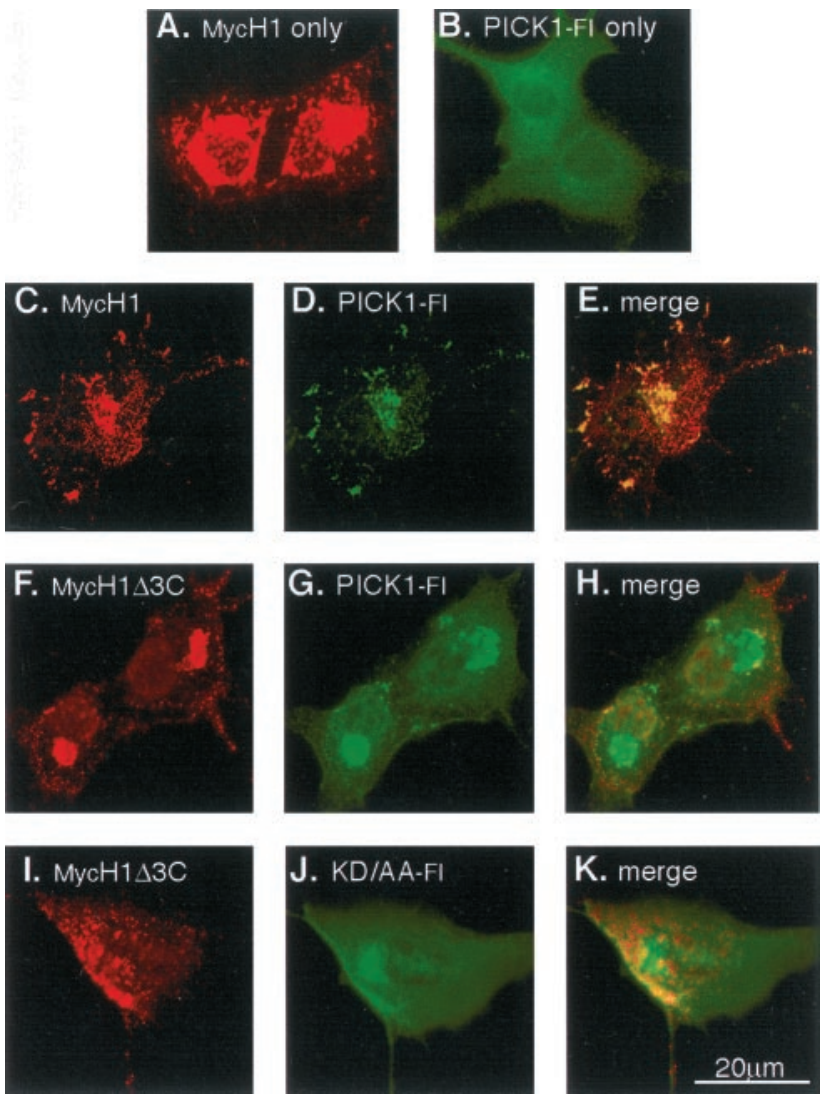

Figure 2. PICK1 is recruited to UNC5H1 clusters in $\operatorname{COS}$ cells. $A-K$, $C O S$ cells were transfected with the indicated MycUnc5h1 and Pick1-Fl constructs. To identify MycH1 expressed on the cell surface, cells were live-labeled with anti-Myc antibodies $(A, C, F, I$, red). Next, the cells were fixed, permeabilized, and immunostained with anti-Flag antibodies to label PICK1-Fl expression $(B, D, G, J$, green); colocalization is shown in yellow $(E, H, K) . A, M y c H 1$ is expressed at the cell membrane in a punctate pattern in the absence of exogenous PICK1.B, PICK1-Fl is expressed in a diffuse cytoplasmic pattern in the absence of exogenous UNC5H1. $C-E$, MycH1 and PICK1-FI

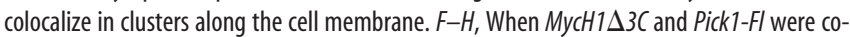
transfected, PICK1-FI remains diffuse and is not recruited to MycH1 clusters. I-K, Similarly, when MycH1 and PICK1-Flko/Aa were cotransfected, PICK1-Flko/AA remains diffuse and is not recruited to MycH1 clusters.

a higher-order complex. COS cells were transfected with various combinations of MycUnc5h1, PKC $\alpha$-Flag, and Pick1-Flag cDNAs. Cells were immunoprecipitated using an anti-Myc antibody and Western blotted to identify coprecipitating $\mathrm{PKC} \alpha$-Fl and PICK1-Fl. We found that PKC $\alpha$-Fl coimmunoprecipitated with $\mathrm{MycH} 1$ only if PKC was first activated by treating the cells with the phorbol ester TPA (Fig. 3I, top, lanes 2, 3). Because COS cells endogenously express PICK1 (Fig. $3 J$ ), we also probed these im-

$\leftarrow$

proteins were used (bottom). Some degradation products of GST-H1ICD are visible, but the full-length protein predominates. C, D, $\operatorname{COS}$ cells were cotransfected with the indicated MycUnc5h and Pick1 constructs and immunoprecipitated with anti-Myc antibodies. The top panels show coprecipitated PICK1 using anti-PICK1 antibodies. The membranes were reprobed with anti-Myc antibodies to indicate UNC5H expression (middle). The bottom panels show equal amounts of total cell lysate probed with anti-PICK1 antibodies as a control for transfection efficiency. C, MycH1 interacts strongly with $\mathrm{PICK} 1, \mathrm{MycH} 2$ interacts less well, and MycH3 shows little interaction. D, MycH1 but not MycH1 $\Delta 3 \mathrm{C}$ interacts with PICK1. PICK1 but not PICK1KD/AA interacts with MycH1. E, UNC5H1 and PICK1 interact in vivo. Extracts of rat hippocampal neurons or $\mathrm{P} 4$ mouse cortex were immunoprecipitated with $6 \mathrm{E} 9$, an antibody specific to UNC5H1. The top panels show coprecipitated PICK1 after Western blotting with an anti-PICK1 antibody. The bottom panels show the same gel blotted with anti-UNC5H1. An UNC5H1 doublet, present here in hippocampal cultures, is frequently seen for the UNC5Hs and likely represents receptor glycosylation. 

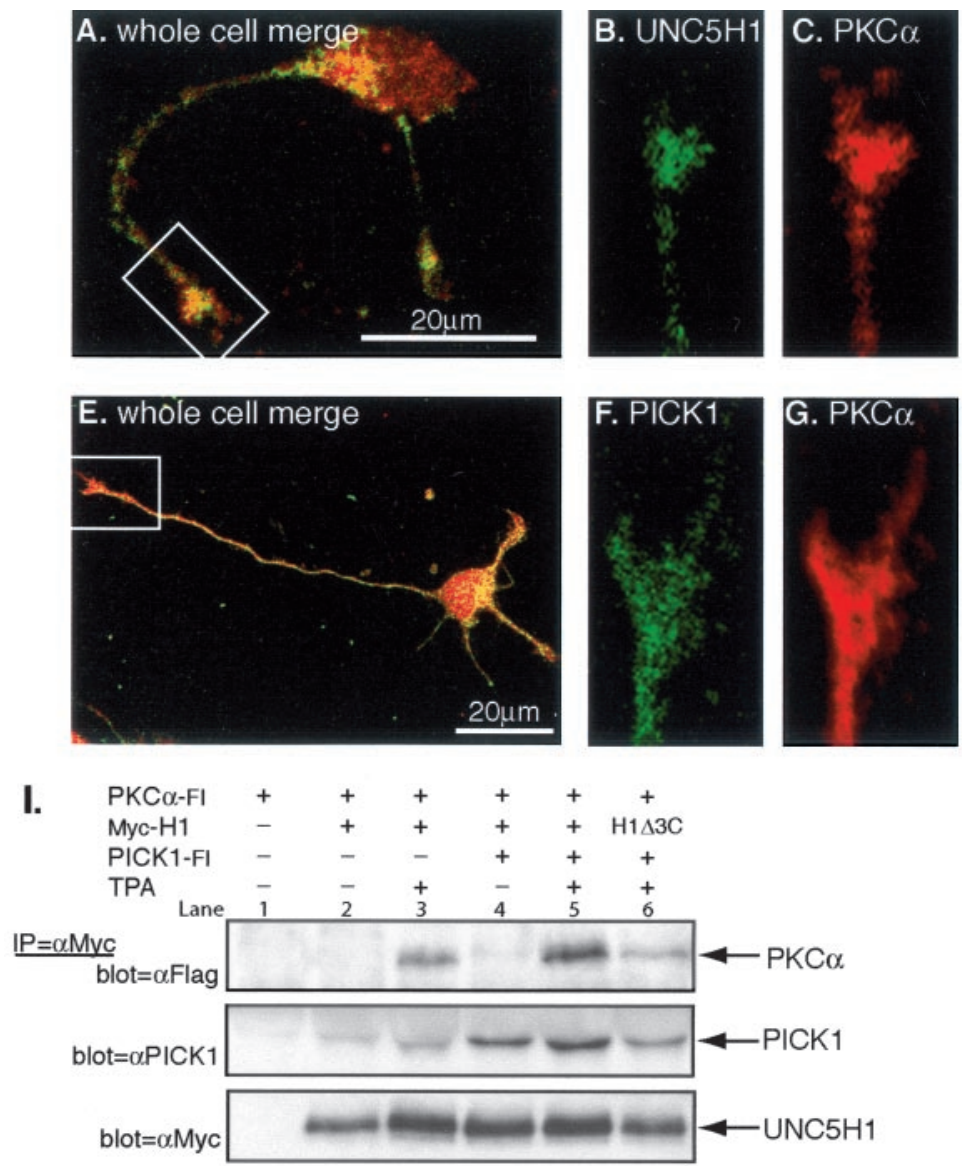

$\underline{\text { total cell lysates }}$

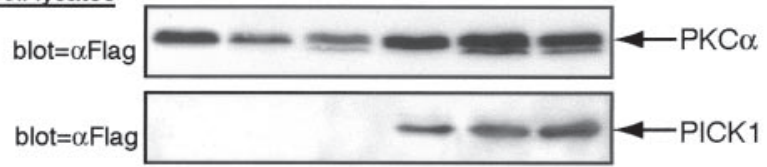

J.

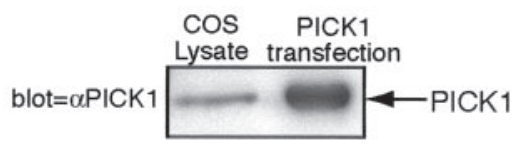

Figure 3. UNC5H1, PICK1, and PKC $\alpha$ are expressed in the growth cone and form a complex in cells. $A-H, 2$ DIV rat hippocampal neurons were immunostained with the indicated antibodies. $A-D$, Endogenous $U N C 5 H 1$ ( $B$, green) and $P K C \alpha(C$, red) colocalize in 2 DIV hippocampal neurons. The merged image is shown ( $D$, yellow). $E-H$, Endogenous PICK1 ( $F$, green) also colocalizes with $\operatorname{PKC} \alpha(G$, red) in the growth cone as seen in the merged image $(H$, yellow). Growth cones from the whole cell pictured in $A$ and $E$, indicated by the white box, are magnified in $B-D$ and $F-H$. I, $C O S$ cells were cotransfected with the indicated MycUnc $5 h$ I, PKC $\alpha$-Flag, Pick1-Flag constructs and immunoprecipitated with anti-Myc antibodies to precipitate UNC5H1. The top panel shows immunoprecipitates blotted with an anti-Flag antibody to identify coprecipitating PKC $\alpha-\mathrm{Fl}$ (Note that PKC $\alpha$-Fl and PICK1-FI can be distinguished because of the difference in their molecular weights; PKC $\alpha$-Fl runs at 80 and PICK1-Fl at $50 \mathrm{kDa}$.) The second panel shows the same immunoprecipitates blotted with an anti-PICK1 antibody to identify coprecipitating endogenous PICK1 and PICK1-Fl. The immunoprecipitates were reprobed with an anti-Myc antibody to confirm equivalent UNC5H1 expression in all lanes. Also shown are total cell lysates probed with anti-Flag to confirm that PKC $\alpha$-Fl and PICK1-Fl expression is equivalent in the indicated lanes. J, COS cells endogenously express PICK1. Total protein lysates from untransfected and Pick1-FI-transfected COS cells were Western blotted using anti-PICK1 antibodies.

munoprecipitations with an anti-PICK1 antibody to determine whether endogenous PICK1 also precipitated in this experiment. We observed that endogenous PICK1 coprecipitated with $\mathrm{MycH} 1$ and PKC $\alpha$-Fl (Fig. 3I, middle), suggesting that PICK1 acts as an adapter molecule to support a complex between $\mathrm{UNC} 5 \mathrm{H} 1$ and $\mathrm{PKC} \alpha$. To test this hypothesis, we kept $\mathrm{MycH} 1$ and PKC $\alpha$-Fl levels constant while increasing PICK1-Fl expression by
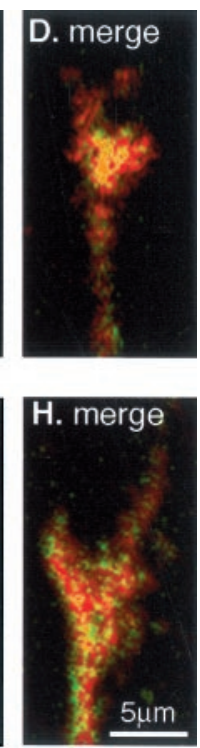

transfection. Coimmunoprecipitation under this condition showed an increased amount of $\mathrm{PKC} \alpha-\mathrm{Fl}$ in a complex with MycH1 in TPA-treated cells (Fig. 3I, top, lanes 4, 5). Furthermore, we showed that $\mathrm{MycH} 1 \Delta 3 \mathrm{C}$, which had a reduced ability to interact with PICK1-Fl, also had a reduced ability to precipitate PKC $\alpha$-Fl (Fig. 3I, top, lane 6). Together, these results suggest that the interaction between $\mathrm{UNC5H} 1$ and $\mathrm{PKC} \alpha$ is not direct but instead, requires PICK1, which acts as an adapter molecule to bring $\mathrm{PKC} \alpha$ to UNC5H1.

\section{UNC5H1 is internalized after PKC activation by a PICK1-dependent mechanism}

$\mathrm{PICK} 1$, in conjunction with $\mathrm{PKC}$, regulates the surface expression of several transmembrane receptors to control their activity (Daw et al., 2000; Xia et al., 2000; Kim et al., 2001; Torres et al., 2001; Hirbec et al., 2003). Because UNC5H1 colocalized with both PICK1 and PKC in hippocampal growth cones, we tested whether the interaction between UNC5H1 and PICK1 regulates the level of UNC5H1 on the cell surface in a PKC-dependent manner. At 14 DIV, hippocampal neurons were infected with viruses expressing $\mathrm{MycH} 1$ and Pick1Fl. To stimulate PKC, TPA was added to some cultures. Because the Myc tag on $\mathrm{MycH} 1$ is extracellular, we examined the surface expression of $\mathrm{MycH} 1$ by livelabeling the cells without permeabilization using a chicken anti-Myc antibody. To examine the intracellular $\mathrm{MycH} 1$, the same cells were then fixed, permeabilized, and incubated with a rabbit anti-Myc antibody. Confocal microscopy showed that when $\mathrm{MycH} 1$ and PICK1-Fl were coexpressed without TPA, MycH1 showed high levels of both intracellular and surface expression (Fig. 4A,B). However, in the presence of TPA the surface expression of $\mathrm{MycH} 1$ was significantly reduced, whereas the intracellular expression of $\mathrm{MycH} 1$ remained high (Fig. 4, compare B,D). Furthermore, we found that internalization of UNC5H1 by TPA was dependent on the interaction of UNC5H1 with PICK1. When $\mathrm{MycH} 1 \Delta 3 \mathrm{C}$ and PICK1-Fl, which have a weak affinity for binding, were coexpressed, the surface expression of $\mathrm{MycH} 1$ did not change in the presence of TPA (Fig. 4E,F). Similarly, when MycH1 and PICK1-FlKD/AA, which also have a weak affinity for binding, were coexpressed, the surface expression of UNC5H1 did not change in the presence of TPA (Fig. 4G,H). To quantify these results, the total area of $\mathrm{MycH} 1$ surface fluorescence and $\mathrm{MycH} 1$ intracellular fluorescence was determined from neurons that also expressed PICK1-Fl. These data were graphed as a ratio of $\mathrm{MycH} 1$ surface expression over $\mathrm{MycH} 1$ intracellular expression and re- 
ferred to as the S/I ratio (Fig. 4I). The S/I ratio of neurons expressing wild-type MycH1 and PICK1-Fl decreased significantly from $1.8 \pm 0.29$ to $0.7 \pm 0.05(p<$ 0.001) after adding TPA (Fig. 4I). This corresponds to a $60 \%$ decrease in $\mathrm{MycH} 1$ surface expression. In contrast, when either $\mathrm{MycH} 1 \Delta 3 \mathrm{C}(\mathrm{S} / \mathrm{I}$ ratio, $1.8 \pm 0.21)$ or PICK1-FlKD/AA (S/I ratio, $1.6 \pm 0.08) \mathrm{mu}$ tants were used in the assay, no significant decrease in surface expression of $\mathrm{MycH} 1 \Delta 3 \mathrm{C}$ or $\mathrm{MycH} 1$, respectively, was observed (Fig. 4I). These results indicate that UNC5H1 is removed from the cell surface after PKC stimulation and this removal requires an interaction between UNC5H1 and PICK1.

Next, we performed a biotinylation assay to confirm that the surface expression of $\mathrm{MycH} 1$ decreases after PKC activation. Hippocampal neurons infected with either $\mathrm{MycH1}$ or $\mathrm{MycH} 1 \Delta 3 \mathrm{C}$ were incubated with or without TPA at $37^{\circ} \mathrm{C}$ for $1 \mathrm{hr}$ to promote internalization, and then placed on ice to stop cellular trafficking. Next, surface proteins were labeled with biotin. After quenching the biotin reaction, cells were lysed and biotinylated proteins were immunoprecipitated using streptavidinagarose beads. The biotinylated proteins were separated by SDS-PAGE and Western blotted with anti-Myc antibodies. As a control, one fifth of the lysate was saved and immunoprecipitated using anti-Myc antibodies to account for the efficiency of infection. Figure $4 \mathrm{~J}$ shows that TPA visibly reduced the amount of biotinylated $\mathrm{MycH} 1$, suggesting that $\mathrm{MycH} 1$ was internalized after PKC activation. To quantify this assay, the amount of biotin-labeled UNC5H1 on untreated cultures was considered $100 \%$ of the surface UNC5H1. After PKC stimulation, the surface expression of UNC5H1 was reduced by $40 \%$ $(p<0.001)$ (Fig. 4L). The surface expression of $\mathrm{MycH} 1 \Delta 3 \mathrm{C}$ appeared slightly less after PKC stimulation; however, after normalizing to the total $\mathrm{MycH} 1 \Delta 3 \mathrm{C}$ expressed in each sample, quantification revealed that surface expression of $\mathrm{MycH} 1 \Delta 3 \mathrm{C}$ did not significantly change after adding TPA (Fig. $4 J, L$ ). We also examined whether the coreceptor of UNC5H1, DCC, was internalized by a similar mechanism in hippocampal cultures. Under the same conditions used for UNC5H1 biotinylation experiments, we found that the surface expression of DCC did not significantly change in the presence or absence of TPA (Fig. $4 K, L$ ). These results support the quantitative immunofluorescence analysis and, together, strongly suggest that the removal of $\mathrm{UNC} 5 \mathrm{H} 1$, but
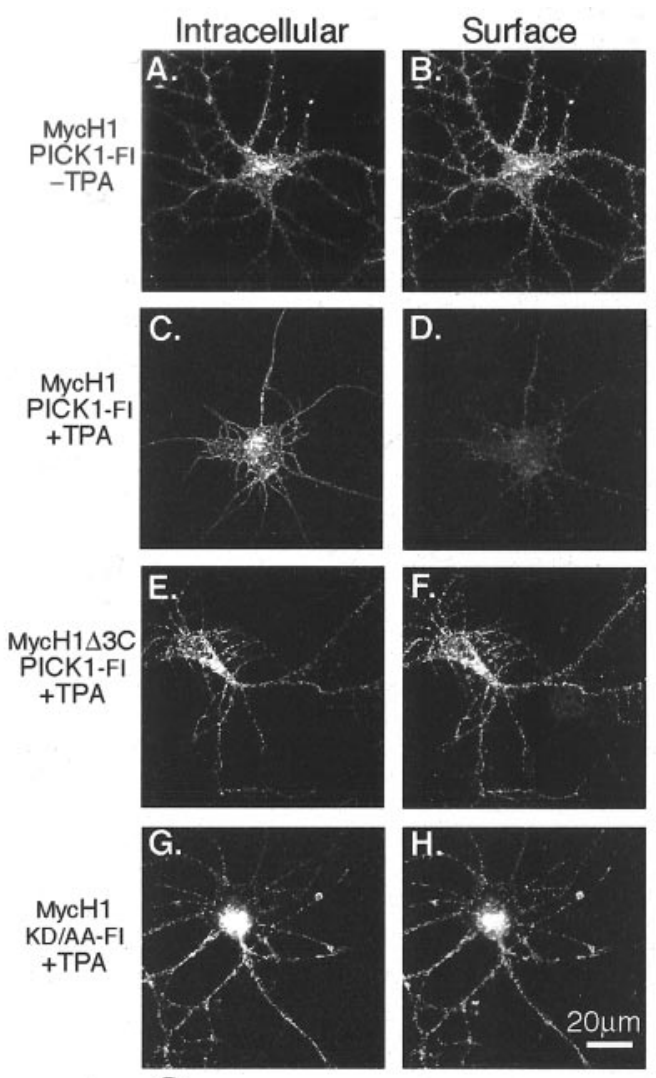

I.
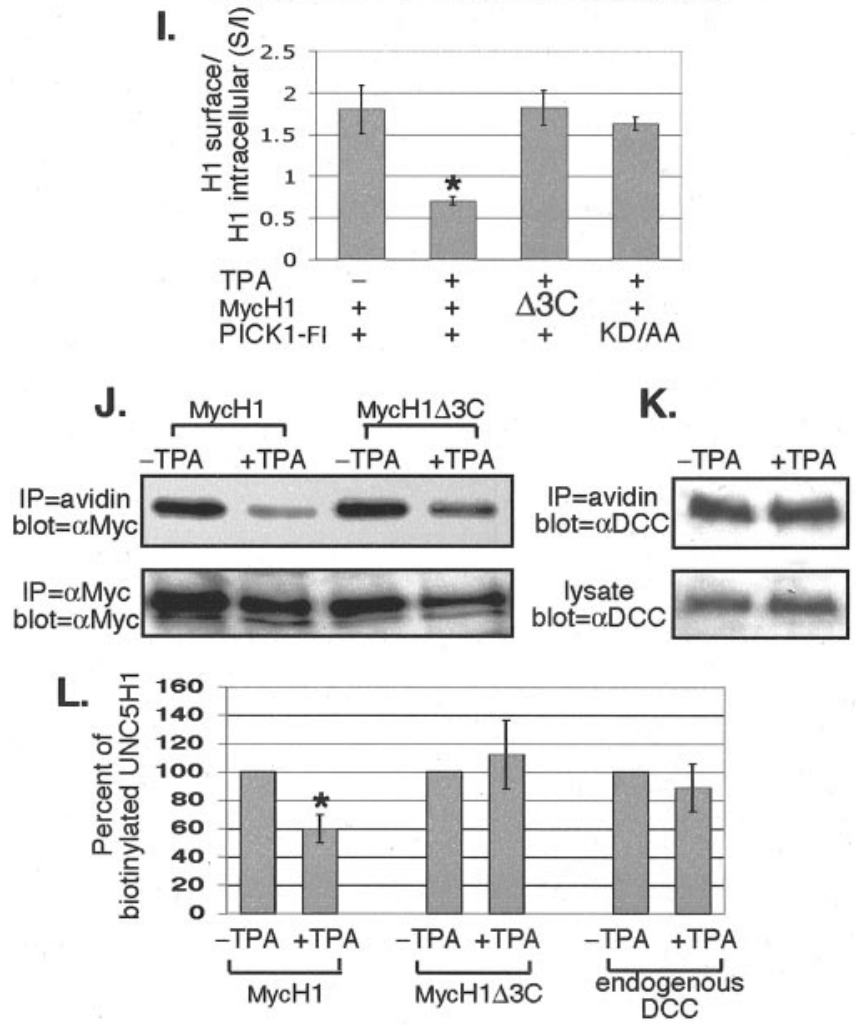

Figure 4. UNC5H1 is internalized after PKC activation in mature neurons. $A-H, 14$ DIV hippocampal neurons were infected with the indicated $M y C H 1$ and Pick1-F/Sindbis viruses. Cells were live-labeled to immunostain surface MycH1 $(B, D, F, H)$, then fixed and permeabilized to immunostain internal $\operatorname{MycH} 1(A, C, E, G)$. The addition of $100 \mathrm{ng} / \mathrm{ml}$ TPA visibly reduced the surface expression of $\mathrm{MycH} 1$ in cells coinfected with MycH1 and Pick1-FI (compare B, D). When MycH1 $\Delta 3 C(E, F)$ or PICK1-FlkD/AA $(G, H)$ were expressed in the assay, then $\mathrm{MycH} 1 \Delta 3 \mathrm{C}$ or MycH1, respectively, was not internalized. I, The results from $A-H$ were quantified by determining the total fluorescence intensity of both the surface-labeled MycH1 and intracellular-labeled MycH1 over the same defined area. Data are graphed as a ratio of surface fluorescence over intracellular fluorescence (S/I). The addition of TPA when MycH1 and PICK1-Fl were expressed resulted in a significant decrease in cell surface expression of MycH1. ${ }^{*} p<0.001 ; t$ test. 
not DCC, from the cell surface depends on the interaction of UNC5H1 with PICK1 and the activation of PKC.

\section{UNC5H1 undergoes PICK1/PKC-dependent trafficking in growth cones}

Because UNC5H1 intracellular trafficking is regulated in mature hippocampal neurons, we tested if a similar mechanism functions in growth cones. Using quantitative immunofluorescence, we determined the surface versus internal $\mathrm{MycH} 1$ expression levels in growth cones of 2 DIV hippocampal neurons. Similar to our results on mature neurons grown $14 \mathrm{DIV}$, when cells were infected with $\mathrm{MycH} 1$ and PICK1-Fl, high levels of clustered $\mathrm{MycH} 1$ staining were visible both inside and on the surface of growth cones (Fig. 5A-C). The addition of TPA significantly reduced the amount of $\mathrm{MycH} 1$ on the surface (Fig. 5D-F). Analysis of the S/I ratio of UNC5H1 expression showed that there was 70\% less $\mathrm{MycH} 1$ on the surface of growth cones in TPA-treated cultures $(1.8 \pm 0.24$ vs $0.6 \pm 0.07, p<0.001)$ (Fig. $5 M)$. Furthermore, infection of either $\mathrm{MycH} 1 \Delta 3 \mathrm{C}$ or PICK1-FlKD/AA did not result in any significant decrease in surface expression of $\mathrm{MycH} 1 \Delta 3 \mathrm{C}$ or $\mathrm{MycH} 1$, respectively (Fig. $5 G-M$ ). These results indicate that $\mathrm{UNC5H} 1$ is removed from the surface of growth cones after PKC activation by a mechanism involving PICK1.

\section{PKC activation inhibits netrin-1-dependent growth cone collapse}

To test whether PICK1/PKC-dependent removal of UNC5H1 from the surface of growth cones affects the response of an axon to netrin-1, we performed collapse assays on hippocampal growth cones. Hippocampal neurons were infected with Sindbis virus expressing $\mathrm{MycH} 12 \mathrm{hr}$ after plating; $24 \mathrm{hr}$ later, the cells extended axons with normal growth cones at the tip (Fig. 6A). When netrin- 1 was added to the media, $74 \pm 6.0 \%$ of the growth cones collapse, as evidenced by a nearly complete loss of lamellipodia and filopodia (Fig. $6 B, E$ ). In contrast, when the cells were pretreated with TPA, to stimulate the PKC-dependent removal of UNC5H1 from the surface of growth cones, significantly fewer growth cones underwent netrin-1-mediated collapse ( $35 \pm 2.1 \%$; $p<0.005)$ compared with cells treated with netrin-1 only (Fig. $6 C, E)$. As a control, we tested whether TPA alone had any effect on growth cone collapse and found that it did not (Fig. 6D,E). Thus, our data suggest that controlling the surface expression of UNC5H1 through a mechanism involving PICK1 and PKC is one way cells regulate the response of a migrating axon to netrin-1.

\section{Discussion}

Very few details are known about netrin-1 signaling as it is mediated specifically through its repellent receptors, the UNC5Hs.

$\leftarrow$

Expression of either MycH1 $\Delta 3 \mathrm{C}$ with PICK1-Fl or MycH1 with PICK1-FlKo/AA shows no significant change in the S/I ratio after adding TPA. Error bars indicate SEM, and in all cases $n>10$. J, K, Surface biotinylation experiments show that $\mathrm{MycH} 1$ is removed from the cell surface after the addition of TPA, whereas DCC remains on the surface. Hippocampal neurons were infected with $\mathrm{MycH} 1$ or $\mathrm{MyCH} 1 \Delta 3 \mathrm{C}$, surface proteins were biotinylated, and cells were precipitated with streptavidin beads. J, Western blotting for MycH1 shows a reduced level of biotinylated MycH1 in the presence of TPA compared with control cultures incubated in the absence of TPA. Western blotting for $\mathrm{H}_{1} \Delta 3 \mathrm{C}$ shows little change in the levels of biotinylated MycH1 $\Delta 3 \mathrm{C}$ in the presence or absence of TPA. A portion of the total cell lysate was immunoprecipitated and Western blotted using anti-Myc antibodies to determine infection efficiency. $K$, Western blotting with an anti-DCC antibody shows that the surface expression of DCC does not change in the presence or absence of TPA. As a loading control, equal amounts of cell lysates were also Western blotted with anti-DCC. $L$, The results from the biotinylation experiments were quantified. The amount of biotinylated $\mathrm{MycH} 1$ or $\mathrm{MycH} 1 \Delta 3 \mathrm{C}$ in cultures without TPA was quantified and normalized as $100 \%$. After the addition of TPA, significantly less MycH 1 is biotinylated compared with controls ( $p<0.001 ; t$ test), whereas MycH1 $\Delta 3$ C shows no significant difference between minus and plus TPA treated cultures. DCC also shows no significant difference between minus and plus TPA treated cultures. ( $n \geq 3)$. Error bars indicate SD.
By performing a yeast two-hybrid screen, we sought to identify proteins that directly affect UNC5H1 signaling. In this study, we report a PDZ-mediated interaction between the netrin-1 receptor UNC5H1 and PICK1. The interaction between UNC5H1 and facilitates the removal of UNC5H1 from the cell surface of (Staudinger et al., 1995, 1997) it may function as a bridge between C5H1 and PKC by binding both molecules simultaneously. (he ability of UNC5H1 to In surface. The intracellular domain of UNC5H1 contains several conserved PKC phosphorylation sites and can be phosphorylated by $\mathrm{PKC}$ in vitro (our unpublished results). Thus, phosphorylation of UNC5H1 by PKC may be the mechanism by which PICK1 promotes the internalization of $\mathrm{UNC} 5 \mathrm{H} 1$. This is consistent with a role for PICK1 priming UNC5Hs for endocytosis, perhaps by reasing it from an interaction with cell-surface scaffolding proilar to one of the proposed models for PICK1 regulation of

\section{Regulated endocytosis generates mechanical forces to} cone induces a repulsive turning response (Xiang et al., 2002). It was found that this repulsion is dependent on local concentraions of intracellular messengers at growth cones because increasstudies have shown that the intracellular environment, for examthe level of $\mathrm{Ca}^{2+}$ or cAMP, is critical during axon guidance influences the turning response for many guidance cues (for centration of global, intracellular second messengers, the actual receptor-mediated mechanism through which the repellent re-

One possible receptor-mediated mechanism for repellent migration involves PKC activation inducing growth cone collapse or in some instances, repulsion, by stimulating receptormediated endocytosis. Endocytosis, in turn, generates mechanical forces that pull membrane off the cell surface to cause retraction. For example, the repellent cue ephrin stimulates endocytosis through Racl to generate cellular forces that result in growth cone collapse (Jurney et al., 2002). This may represent one mechanism whereby growth cones use regulated endocytosis to produce mechanical forces that generate directional cytoskeletal changes during axon guidance (Condic and Letourneau, 1997; Jurney et al., 2002). As for UNC5Hs, one hypothesis is that with PKC activation, UNC5Hs are internalized, generating a force that promotes growth cone collapse away from a source of netrin-1. Although it is unknown whether UNC5H is recycled back to the cell surface, it is possible that successive rounds of endocytosis may continue to generate forces required to propel the cell away from netrin-1. We predict that this repulsion would occur in an intracellular environment low, but not absent, in 

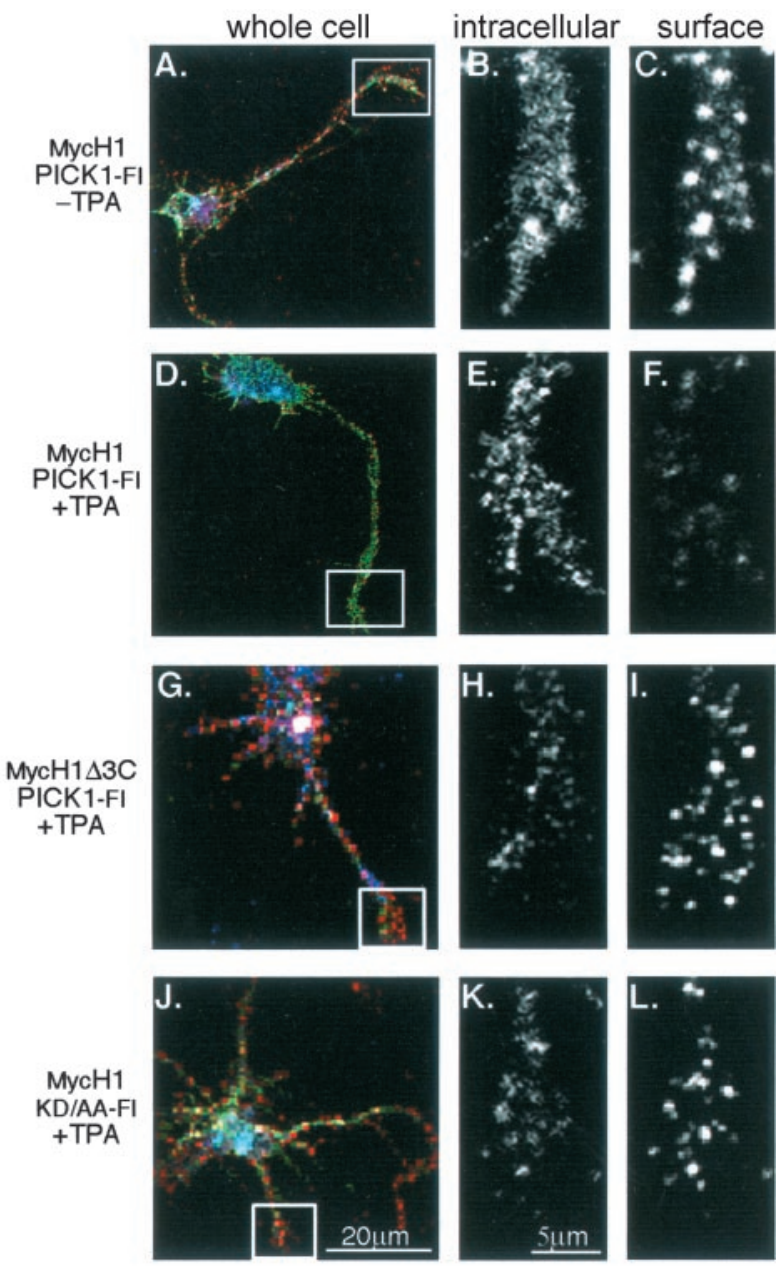

M.

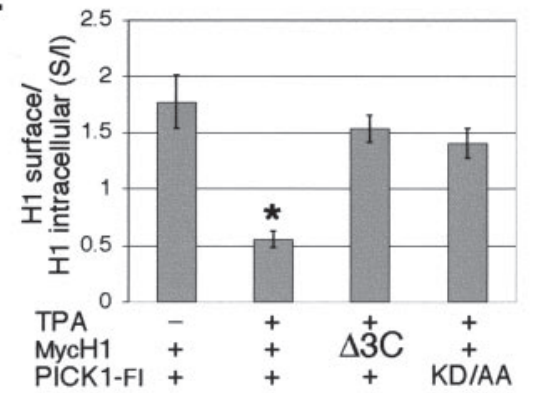

Figure 5. UNC5H1 is internalized after PKC activation in growth cones. $A-L, 2$ DIV hippocampal neurons were infected with the indicated $M y c H 1$ and Pick1-FI Sindbis viruses. Cells were live-labeled to immunostain the surface $\operatorname{Myc} 1(C, F, I, L)$ and then fixed and permeabilized to immunostain the internal MycH1 $(B, E, H, K)$. The first panel in each row $(A, D, G, J)$ shows an entire cell triple labeled for surface MycH1 (red), intracellular MycH1 (green), and PICK1-FI (blue). The following smaller panels show magnified images of the growth cone from the corresponding whole cell. The addition of $100 \mathrm{ng} / \mathrm{ml}$ of TPA visibly reduces the surface expression of MycH1 at the growth cone in cells coexpressing MycH1 and PICK1-FI (compare C, F). When cells expressing MycH1 $\Delta 3 \mathrm{C}(\mathrm{G}-l)$ or PICK1-Flko/AA $(J-L)$ were analyzed, MycH1 $\Delta 3 \mathrm{C}$ or $M y c H 1$, respectively, were not internalized. $M$, The results from $A-H$ were quantified by determining the total fluorescence intensity of both the surface-labeled $\mathrm{MycH} 1$ and intracellularlabeled $\mathrm{MycH} 1$ over the growth cone. Data are graphed as a ratio of surface fluorescence over intracellular fluorescence $(S / I)$. The addition of TPA results in a significant decrease in cellsurface MycH1 when MycH1 and PICK1-Fl are coexpressed. ${ }^{*} p<0.001 ; t$ test. Expression of either MycH1 $\triangle 3$ Cor Pick1-Flkd/Aa shows no significant change in the $S / /$ ratio after adding TPA. Error bars indicate SEM, and in all cases $n>10$.

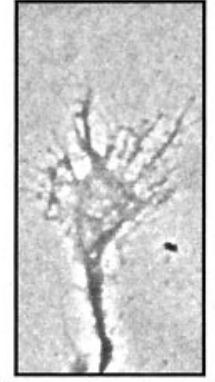

A. no treatment

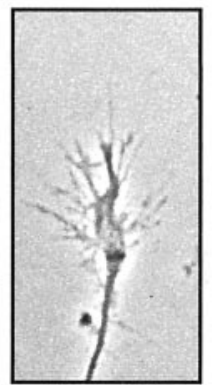

C. TPA

+ netrin-1

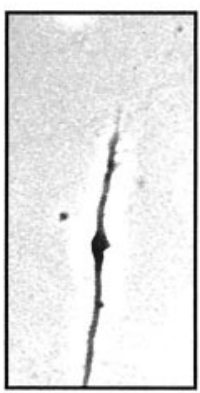

B. netrin-1

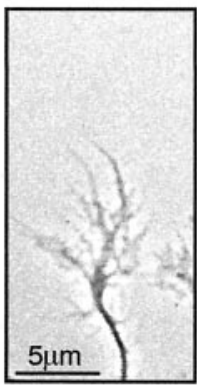

D. TPA
E.

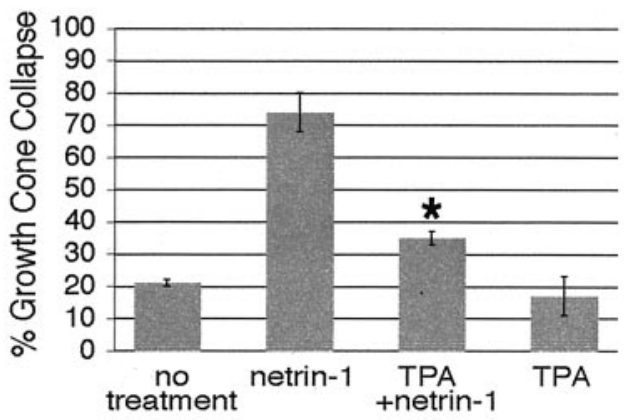

Figure 6. Decreasing surface expression of UNC5H1 after PKC activation prevents netrin-1dependent growth cone collapse. $A-D$, Phase contrast images of 1 DIV hippocampal growth cones were treated as indicated. $E$, The results from $A-D$ were quantified and the percent of collapsed growth cones is shown. $n=50$ cells from three separate experiments. ${ }^{*} p<0.005 ; t$ test compared with treatment with netrin-1 alone.

cAMP, cGMP, and $\mathrm{Ca}^{2+}$ because many studies have shown that this intracellular environment is conducive to repellent migration (Lohof et al., 1992; Ming et al., 1997; Song et al., 1997; Hopker et al., 1999; Hong et al., 2000).

A second way that regulated removal of surface receptors may generate motile forces is by increasing or decreasing adhesion between the cell and the extracellular environment. This was shown for integrin, whose expression on the neuronal cell surface is dynamically regulated by the concentration of extracellular ligand, providing a mechanism whereby neurons maintain proper adhesive interactions over a range of ligand concentrations (Condic and Letourneau, 1997). Because chemotactic ligands are often present in gradients, maintaining appropriate surface expression of receptors is likely critical during axon guidance. UNC5Hs and DCC each contain multiple immunoglobulin domains, a common motif found in adhesive molecules; therefore, their removal from the cell surface could facilitate repulsion through a loss of adhesive contacts with the extracellular matrix. In support of this, the loss of neogenin, a netrin-1 receptor ho- 
mologous to DCC, results in a decrease of cell adhesion in the mammary gland (Srinivasan et al., 2003). Most likely, the endocytic removal of UNC5H1 from the cell surface promotes repulsion through a combination of membrane collapse and loss of extracellular matrix contact.

\section{Regulating endocytosis of the UNC5Hs to direct a switch between repulsion and attraction}

In addition to playing a mechanical role by generating motile forces required for migration, the regulation of receptors on the cell surface may also play an instructive role during axon guidance by dictating directionality. Our data show that UNC5H1 is specifically internalized by a mechanism involving PICK1 and PKC, leaving DCC on the cell surface. In this circumstance, if the intracellular environment (i.e., levels of cAMP and $\mathrm{Ca}^{2+}$ ) is appropriate for attraction, then the specific internalization of UNC5Hs, but not DCC, could lead to a switch from repulsion to attraction in a netrin-1 gradient. This switch may be relevant because netrins are bidirectional guidance cues that both attract and repel neurons and their growth cones (Hong et al., 1999, 2000; Hopker et al., 1999; Shewan et al., 2002). Consequently, the way cells respond to netrin- 1 at intermediate choice points may depend on the availability of different receptors at the cell surface. For example, the availability of the receptor Robo on the surface of axons crossing the midline regulates their responsiveness to the repellent cue Slit (Keleman et al., 2002; Myat et al., 2002). Thus, intracellular trafficking of receptors is one means by which navigating growth cones quickly adjust their sensitivity to extracellular guidance cues at intermediate choice points.

\section{Sequestering UNC5H1 could prevent unnecessary apoptosis}

The discovery that maintaining UNC5H1 on the cell surface does not occur simply by default but, instead, is a regulated cellular process has implications toward understanding how a cell can modulate the various functions of netrin-1 and its receptors. Not only do UNC5Hs function during netrin-1-dependent cell and axon migration but they also induce netrin-1-independent apoptosis (Llambi et al., 2001; Tanikawa et al., 2003; Williams et al., 2003). Subcellular trafficking of UNC5H1 may be important for separating these two distinct functions. Constitutive expression of UNC5H1 on the surface of cells leads to programmed cell death (Llambi et al., 2001; Tanikawa et al., 2003; Williams et al., 2003). However, if UNC5H1 were shuttled to endosomal compartments, then UNC5Hs may not be able to send an apoptotic signal. In support of this hypothesis, we find that expression of the intracellular domain of UNC5H1 as a cytoplasmic protein results in significantly less apoptosis than UNC5H1 that is expressed at the cell membrane (our unpublished results). Thus, maintaining UNC5H1 in intracellular stores would allow the receptor to be readily available for mobilization during axon guidance, but sequestered to prevent unintentional apoptosis.

In sum, we find that the internalization of UNC5H1 is regulated by a mechanism involving PICK1 and PKC and there are at least two models for how this could control axon guidance. One is that internalization of UNC5H after PKC activation mediates repulsion by generating mechanical forces away from a source of netrin-1. The second is that specific internalization of $\mathrm{UNC} 5 \mathrm{H}$ after PKC activation mediates attraction when DCC remains on the cell surface in a netrin-1 gradient. These models are not mutually exclusive and the outcome likely reflects the intracellular signaling environment. Because UNC5H1 functions in diverse cellular processes including cell and axon repulsion and apoptosis, regulated subcellular trafficking of this receptor may provide one mechanism to control the final outcome of UNC5H signaling.

\section{References}

Ackerman SL, Kozak LP, Przyborski SA, Rund LA, Boyer BB, Knowles BB (1997) The mouse rostral cerebellar malformation gene encodes an UNC-5-like protein. Nature 386:838-842.

Alcantara S, Ruiz M, De Castro F, Soriano E, Sotelo C (2000) Netrin 1 acts as an attractive or as a repulsive cue for distinct migrating neurons during the development of the cerebellar system. Development 127:1359-1372.

Bloch-Gallego E, Ezan F, Tessier-Lavigne M, Sotelo C (1999) Floor plate and netrin-1 are involved in the migration and survival of inferior olivary neurons. J Neurosci 19:4407-4420.

Boudin H, Doan A, Xia J, Shigemoto R, Huganir RL, Worley P, Craig AM (2000) Presynaptic clustering of mGluR7a requires the PICK1 PDZ domain binding site. Neuron 28:485-497.

Chung HJ, Xia J, Scannevin RH, Zhang X, Huganir RL (2000) Phosphorylation of the AMPA receptor subunit GluR2 differentially regulates its interaction with PDZ domain-containing proteins. J Neurosci 20:7258-7267.

Condic ML, Letourneau PC (1997) Ligand-induced changes in integrin expression regulate neuronal adhesion and neurite outgrowth. Nature 389:852-856

Daw MI, Chittajallu R, Bortolotto ZA, Dev KK, Duprat F, Henley JM, Collingridge GL, Isaac JT (2000) PDZ proteins interacting with C-terminal GluR2/3 are involved in a PKC-dependent regulation of AMPA receptors at hippocampal synapses. Neuron 28:873-886.

Dev KK, Nakajima Y, Kitano J, Braithwaite SP, Henley JM, Nakanishi S (2000) PICK1 interacts with and regulates PKC phosphorylation of mGLUR7. J Neurosci 20:7252-7257.

Duggan A, Garcia-Anoveros J, Corey DP (2002) The PDZ domain protein PICK1 and the sodium channel $\mathrm{BNaC} 1$ interact and localize at mechanosensory terminals of dorsal root ganglion neurons and dendrites of central neurons. J Biol Chem 277:5203-5208.

Engelkamp D (2002) Cloning of three mouse Unc5 genes and their expression patterns at mid-gestation. Mech Dev 118:191-197.

Finger JH, Bronson RT, Harris B, Johnson K, Przyborski SA, Ackerman SL (2002) The netrin 1 receptors unc $5 \mathrm{~h} 3$ and dcc are necessary at multiple choice points for the guidance of corticospinal tract axons. J Neurosci 22:10346-10356.

Hanley JG, Khatri L, Hanson PI, ZiffEB (2002) NSF ATPase and alpha/betaSNAPs disassemble the AMPA receptor-PICK1 complex. Neuron 34:53-67.

Hedgecock EM, Culotti JG, Hall DH (1990) The unc-5, unc-6 and unc-40 genes guide the circumferential migrations of pioneer axons and mesodermal cells on the epidermis in C. elegans. Neuron 4:61-85.

Hirbec H, Perestenko O, Nishimune A, Meyer G, Nakanishi S, Henley JM, Dev KK (2002) The PDZ proteins PICK1, GRIP, and syntenin bind multiple glutamate receptor subtypes. Analysis of PDZ binding motifs. J Biol Chem 277:15221-15224.

Hirbec H, Francis JC, Lauri SE, Braithwaite SP, Coussen F, Mulle C, Dev KK, Couthino V, Meyer G, Isaac JT, Collingridge GL, Henley JM (2003) Rapid and differential regulation of AMPA and kainate receptors at hippocampal mossy fibre synapses by PICK1 and GRIP. Neuron 37:625-638.

Hong K, Hinck L, Nishiyama M, Poo MM, Tessier-Lavigne M, Stein E (1999) A ligand-gated association between cytoplasmic domains of UNC5 and DCC family receptors converts netrin-induced growth cone attraction to repulsion. Cell 97:927-941.

Hong K, Nishiyama M, Henley J, Tessier-Lavigne M, Poo M (2000) Calcium signalling in the guidance of nerve growth by netrin-1. Nature 403:93-98.

Hopker VH, Shewan D, Tessier-Lavigne M, Poo M, Holt C (1999) Growthcone attraction to netrin-1 is converted to repulsion by laminin-1. Nature 401:69-73.

Huang X, Cheng HJ, Tessier-Lavigne M, Jin Y (2002) MAX-1, a novel PH/ MyTH4/FERM domain cytoplasmic protein implicated in netrinmediated axon repulsion. Neuron 34:563-576.

Jurney WM, Gallo G, Letourneau PC, McLoon SC (2002) Racl-mediated endocytosis during ephrin-A2- and semaphorin $3 \mathrm{~A}$-induced growth cone collapse. J Neurosci 22:6019-6028.

Keino-Masu K, Masu M, Hinck L, Leonardo ED, Chan SS, Culotti JG, TessierLavigne M (1996) Deleted in Colorectal Cancer (DCC) encodes a netrin receptor. Cell 87:175-185. 
Keleman K, Dickson BJ (2001) Short and long-range repulsion by the Drosophila Unc5 netrin receptor. Neuron 32:605-617.

Keleman K, Rajagopalan S, Cleppien D, Teis D, Paiha K, Huber LA, Technau GM, Dickson BJ (2002) Comm sorts robo to control axon guidance at the Drosophila midline. Cell 110:415-427.

Kim CH, Chung HJ, Lee HK, Huganir RL (2001) Interaction of the AMPA receptor subunit GluR2/3 with PDZ domains regulates hippocampal long-term depression. Proc Natl Acad Sci USA 98:11725-11730.

Leonardo ED, Hinck L, Masu M, Keino-Masu K, Ackerman SL, TessierLavigne M (1997) Vertebrate homologues of C. elegans UNC-5 are candidate netrin receptors. Nature 386:833-838.

Leung-Hagesteijn C, Spence AM, Stern BD, Zhou Y, Su MW, Hedgecock EM, Culotti JG (1992) UNC-5, a transmembrane protein with immunoglobulin and thrombospondin type 1 domains, guides cell and pioneer axon migrations in C. elegans. Cell 71:289-299.

Lin WJ, Chang YF, Wang WL, Huang CY (2001) Mitogen-stimulated TIS21 protein interacts with a protein-kinase-C $\alpha$-binding protein rPICK1. Biochem J 354:635-643.

Llambi F, Causeret F, Bloch-Gallego E, Mehlen P (2001) Netrin-1 acts as a survival factor via its receptors UNC5H and DCC. EMBO J 20:2715-2722.

Lohof AM, Quillan M, Dan Y, Poo MM (1992) Asymmetric modulation of cytosolic cAMP activity induces growth cone turning. J Neurosci 12:1253-1261.

Ming GL, Song HJ, Berninger B, Holt CE, Tessier-Lavigne M, Poo MM (1997) cAMP-dependent growth cone guidance by netrin-1. Neuron 19:1225-1235.

Myat A, Henry P, McCabe V, Flintoft L, Rotin D, Tear G (2002) Drosophila Nedd4, a ubiquitin ligase, is recruited by commissureless to control cell surface levels of the roundabout receptor. Neuron 35:447-459.

Osten P, Srivastava S, Inman GJ, Vilim FS, Khatri L, Lee LM, States BA, Einheber S, Milner TA, Hanson PI, Ziff EB (1998) The AMPA receptor GluR2 C terminus can mediate a reversible, ATP-dependent interaction with NSF and alpha- and beta-SNAPs. Neuron 21:99-110.

Perez JL, Khatri L, Chang C, Srivastava S, Osten P, Ziff EB (2001) PICK1 targets activated protein kinase $\mathrm{C} \alpha$ to AMPA receptor clusters in spines of hippocampal neurons and reduces surface levels of the AMPA-type glutamate receptor subunit 2. J Neurosci 21:5417-5428.

Petersen OH, Cancela JM (2000) Attraction or repulsion by local $\mathrm{Ca}(2+)$ signals. Curr Biol 10:R311-R314.

Shewan D, Dwivedy A, Anderson R, Holt CE (2002) Age-related changes underlie switch in netrin-1 responsiveness as growth cones advance along visual pathway. Nat Neurosci 5:955-962.
Song HJ, Poo MM (1999) Signal transduction underlying growth cone guidance by diffusible factors. Curr Opin Neurobiol 9:355-363.

Song HJ, Ming GL, Poo MM (1997) cAMP-induced switching in turning direction of nerve growth cones. Nature 388:275-279.

Srinivasan K, Strickland P, Valdes A, Shin GC, Hinck L (2003) Netrin-1/ neogenin interaction stabilizes multipotent progenitor cap cells during mammary gland morphogenesis. Dev Cell 4:371-382.

Staudinger J, Zhou J, Burgess R, Elledge SJ, Olson EN (1995) PICK1: a perinuclear binding protein and substrate for protein kinase $\mathrm{C}$ isolated by the yeast two-hybrid system. J Cell Biol 128:263-271.

Staudinger J, Lu J, Olson EN (1997) Specific interaction of the PDZ domain protein PICK1 with the $\mathrm{COOH}$ terminus of protein kinase C-alpha. J Biol Chem 272:32019-32024.

Tanikawa C, Matsuda K, Fukuda S, Nakamura Y, Arakawa H (2003) p53RDL1 regulates p53-dependent apoptosis. Nat Cell Biol 5:216-223.

Tong J, Killeen MT, Steven R, Binns KL, Culotti JG, Pawson T (2001) Netrin stimulates tyrosine phosphorylation of the UNC-5 family of netrin receptors and induces Shp2 binding to the RCM cytodomain. J Biol Chem 276:40917-40925.

Torres GE, Yao WD, Mohn AR, Quan H, Kim KM, Levey AI, Staudinger J, Caron MG (2001) Functional interaction between monoamine plasma membrane transporters and the synaptic PDZ domain-containing protein PICK1. Neuron 30:121-134.

Torres R, Firestein BL, Dong H, Staudinger J, Olson EN, Huganir RL, Bredt DS, Gale NW, Yancopoulos GD (1998) PDZ proteins bind, cluster, and synaptically colocalize with Eph receptors and their ephrin ligands. Neuron 21:1453-1463.

Vojtek AB, Hollenberg SM, Cooper JA (1993) Mammalian Ras interacts directly with the serine/threonine kinase Raf. Cell 74:205-214.

Williams ME, Strickland P, Watanabe K, Hinck L (2003) UNC5H1 induces apoptosis via its juxtamembrane region through an interaction with NRAGE. J Biol Chem 278:17483-17490.

Xia J, Zhang X, Staudinger J, Huganir RL (1999) Clustering of AMPA receptors by the synaptic PDZ domain-containing protein PICK1. Neuron 22:179-187.

Xia J, Chung HJ, Wihler C, Huganir RL, Linden DJ (2000) Cerebellar longterm depression requires PKC-regulated interactions between GluR2/3 and PDZ domain-containing proteins. Neuron 28:499-510.

Xiang Y, Li Y, Zhang Z, Cui K, Wang S, Yuan XB, Wu CP, Poo MM, Duan S (2002) Nerve growth cone guidance mediated by G protein-coupled receptors. Nat Neurosci 5:843-848. 